\title{
Comparison of the methods of the phase transfer catalysis and hydroperox- ide in the epoxidation of 1,5,9-cyclododecatriene
}

\author{
Grzegorz Lewandowski \\ Szczecin University of Technology, Institute of Organic Chemical Technology, Pulaskiego 10, 70-322 Szczecin, Poland, \\ e-mail: grzegorz.lewandowski@ps.pl
}

The process of the epoxidation of cis,trans,trans-1,5,9-cyclododecatriene (CDT) to 1,2-epoxy-5,9cyclododecadiene (ECDD) with the $30 \%$ aqueous hydrogen peroxide under the phase transfer conditions and with tert-butyl hydroperoxide under the homogeneous conditions was investigated. Onium salts such as Aliquat ${ }^{\circledR} 336$, Arquad ${ }^{\circledast} 2 \mathrm{HT}$, methyltrioctylammonium bromide and the $\mathrm{Na}_{2} \mathrm{WO}_{4} / \mathrm{H}_{3} \mathrm{PO}_{4}$ catalyst system are very active under the phase transfer catalysis (PTC) conditions for the selective epoxidation of cis,trans,trans1,5,9-cyclododecatiene (PTC method). These catalytic systems were found to be as active and selective as the homogeneous phase system $\mathrm{Mo}(\mathrm{CO})_{6} / \mathrm{TBHP}$ (hydroperoxide method).

Keywords: epoxidation, 1,5,9-cyclododecatriene, phase transfer catalysis, hydrogen peroxide, tert-butyl hydroperoxide.

Presented at VII Conference Wasteless Technologies and Waste Management in Chemical Industry and Agriculture, Międzyzdroje, 12 - 15 June, 2007.

\section{INTRODUCTION}

Epoxides are useful industrial intermediates such as e.g. propylene oxide which is used at the root of the synthesis of polyether polyols used for the production of polyurethane foams, and also used for the synthesis of propylene glycol for the elaboration of unsaturated polyester resins ${ }^{1}$. Epoxides are also one of the most important and versatile intermediates for fine chemical and specialty chemicals synthesis such as epoxy resin, surfactants, paints, adhesives, surface coating agents, and in addition to a range of bioactive substances and flavour and fragrances ${ }^{2}$.

Industrial production of epoxides usually employs a different oxygen source. However, the origin of the oxygen atom is rarely dioxygen itself, thus another peroxygen atomdonor oxidant must be used. Increasingly stringent environmental legislation as well as economic factors lead to a preference of the oxidations involving dioxygen, hydrogen peroxide, and alkyl hydroperoxides such as tert-butyl peroxide (TBHP) ${ }^{1}$.

For the industrial synthesis, TBHP is probably one of the best oxygen sources because it is thermally stable, not very corrosive, relatively safe, and well soluble in a nonpolar solvent. Using the TBHP after its activation by an appropriate transition metal complex leads to selective oxidations. However, that requires commercialisation or recycling of a large amount of the alcohol co-product. The tert-butyl alcohol, co-produced from tert-butyl hydroperoxide, can be blended with gasoline to inhibit the engine knock or dehydrated to make isobutylene for the conversion to methyl tert-butyl ether, also a gasoline blending component ${ }^{1}$. Similarly, the 1-phenylethanol obtained as a co-product from the ethylbenzene hydroperoxide reaction is dehydrated to produce styrene.

On the other hand, there is a strong need for the development of alternative epoxidation methods that are cleaner, safer, and more environmentally friendly which employ safer oxidants and produce little waste. The processes should be efficient in both the energy and raw materials consumption and produce little waste ${ }^{3}$. From this point of view the employment of hydrogen peroxide is an attractive option both on the environmental and the economic ground $^{4}$. It is inexpensive, relatively safe and easy to handle, and produces water as the sole co-product of reduction. Several catalytic systems have been reported for the epoxidation of a wide range of alkenes with an aqueous hydrogen peroxide as an oxidant in the last two decades. Interesting results of olefine epoxidation were obtained with tungsten catalytic systems under the phase transfer catalysis conditions $(\mathrm{PTC})^{5-8}$.

In this paper the results of the studies on the epoxidation of cis,trans,trans-1,5,9-cyclododecatriene (CDT) by the $\mathrm{Mo}(\mathrm{CO})_{6} / \mathrm{TBHP}$ system (hydroperoxide method) and hydrogen peroxide under the phase transfer catalysis conditions (PTC method), have been presented.

\section{MATERIALS AND METHODS}

\section{Chemicals}

All experiments were performed with the following reagents: $46 \%$ of the TBHP solution in 1,2-dichloroethane (DCE), which was received in the extraction process of 70\% TBHP water solution (Aldrich) by 1,2dichloroethane', an aqueous solutions of $\mathrm{H}_{2} \mathrm{O}_{2}(30 \%)$, phosphorous(V) acid (85\%), and 1,2-dichloroethane were purchased from POCh, Poland; cis,trans,trans-1,5,9cyclododecatriene (CDT), methyltrioctylammonium chloride (Aliquat ${ }^{\circledR 3}$ 36), tetraethylammonium bromide, methyltrioctylammonium bromide, and dodecane were obtained from Aldrich; sodium (tetraoxo)tungstate(VI), tetraethylammonium chloride, tetrapropylammonium bromide, tetrabutylammonium hydrogensulfate and dimethyl[dioctadecyl $(76 \%)+$ dihexadecyl $(24 \%)]$ ammonium chloride $\left(\operatorname{Arquad}^{\circledR} 2 \mathrm{HT}\right.$ ) were purchased from Fluka; tetrabutlammonium bromide and molybdenum hexacarbonyl, $\mathrm{Mo}(\mathrm{CO})_{6}(>95 \%)$ were obtained from Merck-Schuchardt. 


\section{Procedure}

The catalytic epoxidation reactions with hydrogen peroxide as an oxidant were carried out under the pressurelow conditions in the apparatus described elsewhere ${ }^{\mathbf{1 0}}$. In a typical experiment, sodium (tetraoxo)tungstate(VI), 30\% aqueous $\mathrm{H}_{2} \mathrm{O}_{2}$, and $85 \% \mathrm{H}_{3} \mathrm{PO}_{4}$ were added into the 25 $\mathrm{cm}^{3}$ flask at room temperature and then stirred for 15 min. Then the solution of ammonium salt in 1,2dichloroethane was added dropwise with stirring. Stirring was continued for an additional $15 \mathrm{~min}$. To the resultant solution, the weighed amount of CDT was added and then the flask was immersed in the ultrathermostat with a determined temperature. After reaching a desired temperature, $30 \% \mathrm{H}_{2} \mathrm{O}_{2}$ was added dropwise. The reaction was maintained at $50^{\circ} \mathrm{C}$ for $45 \mathrm{~min}$ with vigorous stirring. After the reaction, the reaction mixture was rapidly cooled to room temperature in order to stop the reaction. The organic phase was analyzed chromatographically, and the concentration of CDT and ECDD in the product was determined. The $\mathrm{H}_{2} \mathrm{O}_{2}$ concentration in the aqueous phase was determined by an iodometric method ${ }^{\mathbf{1 1}}$.

All the experiments with the use of TBHP were performed according to the following procedure: the precisely weighed amount of CDT and the solution of TBHP in DCE were placed into the three-necked flask of the capacity of $25 \mathrm{~cm}^{3}$, fitted with a thermometer, reflux condenser and a mechanical mixer. The flask was later immersed in an oil bath. When the temperature of the reaction mixture reached $70^{\circ} \mathrm{C}$, the molybdenum catalyst dissolved in the DCE was added immediately. After finishing the reaction, the flask with the post-reaction mixture was cooled quickly to room temperature to stop the reaction. The content of the flask was weighed and the chromatographic and iodometry analysis ${ }^{\mathbf{1 1}}$ was taken in order to make mass balance.

\section{RESULTS AND DISCUSSION}

\section{PTC method}

The investigation of the influence of the type of the phase transfer catalyst on the CDT epoxidation were per- formed with the use of different ammonium salts (PTA): tetraethylammonium chloride, methyltrioctylammonium chloride (Aliquat $\left.{ }^{\circledR} 336\right)$, dimethyl[dioctadecyl $(76 \%)+$ dihexadecyl $(24 \%)$ ]ammonium chloride (Arquad $\left.{ }^{\circledR} 2 \mathrm{HT}\right)$, tetrabutylammonium hydrogensulfate, tetraethylammonium bromide, tetrapropylammonium bromide, tetrabutlammonium bromide, and methyltrioctylammonium bromide. The initial parameters of the syntheses were as follows: the temperature of $50^{\circ} \mathrm{C}$, the $\mathrm{CDT}: \mathrm{H}_{2} \mathrm{O}_{2}$ mole ratio 1:1, the $\mathrm{W}: \mathrm{P}: \mathrm{PTA}$ mole ratio 5:2.5:1, the PTA content 0.7 mass $\%$, and the reaction time was $45 \mathrm{~min}$ (Table 1).

In the presence of Aliquat ${ }^{\circledR} 336$, Arquad $^{\circledR} 2 \mathrm{HT}$, and methyltrioctylammonium bromide the maximum degree of the conversion of $\mathrm{H}_{2} \mathrm{O}_{2}(96.6-97.6$ mole \%) were obtained. In the presence of these salts the degrees of the conversion of CDT were also high (Table 1). However, the maximum ECDD selectivity both in relation to $\mathrm{H}_{2} \mathrm{O}_{2}$ and in relation to the CDT consumed were obtained in the presence of tetrabutylammonium hydrogensulfate. Somewhat lower selectivities were obtained in the presence of Aliquat ${ }^{\circledR} 336$, Arquad $^{\circledR} 2 \mathrm{HT}$, tetrabutlammonium bromide, and methyltrioctylammonium bromide. Other investigated salts were inactive as the phase transfer catalysts in the epoxidation of the CDT.

The studies demonstrate a considerable influence of the CDT: $\mathrm{H}_{2} \mathrm{O}_{2}$ mole ratio on the CDT epoxidation. The initial parameters of the syntheses were the following: PTA - Aliquat ${ }^{\circledR} 336$, the PTA content 0.7 mass $\%$, temperature $60^{\circ} \mathrm{C}$, the W:P:PTA mole ratio 5:2.5:1, and the reaction time was 45 min (Table 2).

Initially, the yield of the ECCD increases with increase of the mole ratio of CDT to $\mathrm{H}_{2} \mathrm{O}_{2}$, then the yield was found to decrease with the increasing mole ratio. The maximum yield of the ECDD in relation to the CDT and $\mathrm{H}_{2} \mathrm{O}_{2}$ introduced, was obtained at the CDT: $\mathrm{H}_{2} \mathrm{O}_{2}$ mole ratio reaching $1: 1$ and $3: 1$, respectively.

At the study of the effect of the reaction time the initial parameters of the syntheses were as follows: PTA Aliquat ${ }^{\circledR}$ 336, the PTA content 0.7 mass $\%$, the temperature $60^{\circ} \mathrm{C}$, the CDT: $\mathrm{H}_{2} \mathrm{O}_{2}$ mole ratio $1: 1$, and the W:P:PTA mole ratio 5:2.5:1 (Table 3).

Table 1. The result of the CDT epoxidation under the PTC condition in relation to the ammonium salt type

\begin{tabular}{|c|c|c|c|c|c|c|c|c|}
\hline & \multicolumn{8}{|c|}{ Type of ammonium salt } \\
\hline & 1 & 2 & 3 & 4 & 5 & 6 & 7 & 8 \\
\hline $\mathrm{H}_{2} \mathrm{O}_{2}$ conversion [mole $\%$ ] & 0.86 & 97.56 & 97.15 & 17.59 & 1.51 & 1.73 & 6.87 & 96.59 \\
\hline CDT conversion [mole\%] & 8.22 & 78.33 & 82.41 & 20.69 & 13.97 & 2.04 & 8.90 & 80.70 \\
\hline ECDD selectivity/ $\mathrm{H}_{2} \mathrm{O}_{2}[\mathrm{~mole} \%]$ & 9.25 & 42.69 & 36.48 & 82.69 & 4.80 & 5.80 & 57.77 & 43.42 \\
\hline ECDD selectivity/CDT [mole\%] & 1.00 & 55.12 & 43.88 & 73.48 & 0.53 & 5.13 & 47.16 & 53.37 \\
\hline
\end{tabular}

Table 2. The result of the CDT epoxidation under the PTC condition in relation to the $\mathrm{CDT}: \mathrm{H}_{2} \mathrm{O}_{2}$ ratio

\begin{tabular}{|l|c|c|c|c|c|}
\hline & \multicolumn{5}{|c|}{ CDT: $\mathrm{H}_{2} \mathrm{O}_{2}$ mole ratio } \\
\hline & 0.5 & 1 & 2 & 3 & 5 \\
\hline Yield of $\mathrm{ECDD} / \mathrm{H}_{2} \mathrm{O}_{2}[\mathrm{~mole} \%]$ & 5.30 & 38.31 & 62.19 & 68.92 & 59.62 \\
\hline Yield of ECDD/CDT $[$ mole\%] & 11.15 & 40.13 & 32.17 & 24.10 & 11.87 \\
\hline
\end{tabular}

Table 3. The result of the CDT epoxidation under the PTC condition in relation to the reaction time

\begin{tabular}{|l|l|l|l|l|l|c|}
\hline & \multicolumn{5}{|c|}{ Reaction time, $\min$} \\
\hline & 15 & 30 & 45 & 60 & 90 & 180 \\
\hline $\mathrm{W} \mathrm{ECDD} / \mathrm{H}_{2} \mathrm{O}_{2}[\mathrm{~mole} \%]$ & 40.12 & 41.54 & 42.09 & 41.18 & 38.31 & 28.21 \\
\hline $\mathrm{W} \mathrm{ECDD/CDT}[\mathrm{mole} \%]$ & 42.38 & 42.43 & 43.11 & 42.27 & 40.13 & 29.26 \\
\hline
\end{tabular}


The changes in the reaction time do not have a significant influence on the yield of the ECDD in relation to the CDT and $\mathrm{H}_{2} \mathrm{O}_{2}$ introduced within a period of $15-60$ $\mathrm{min}$. However, after $60 \mathrm{~min}$ the yields decreased rapidly. It is worthy of note that the maximum yield was obtained in a relatively short reaction time of $15-45 \mathrm{~min}$.

The changes of the ECDD yield in relation to the temperature are shown in Table 4. The initial parameters of the syntheses were as follows: PTA Aliquat ${ }^{\circledR} 336$, the PTA content 0.7 mass $\%$, the CDT: $\mathrm{H}_{2} \mathrm{O}_{2}$ mole ratio $1: 1$, the W:P:PTA mole ratio 5:2.5:1, and the reaction time 45 $\min$.

As the temperature was increased from 20 to $50^{\circ} \mathrm{C}$, an increase of the ECDD yield both in relation to the CDT and $\mathrm{H}_{2} \mathrm{O}_{2}$ introduced was observed from 26.03 to 43.17 mole \% and from 25.44 to 41.65 mole\%, respectively. Somewhat lower ECDD yields were obtained at higher temperatures.

A decrease of the ECDD yields with increasing the temperature (above $50^{\circ} \mathrm{C}$ ) and time (above $60 \mathrm{~min}$ ) probably results from a considerable reactivity of oxirane ring.

\section{Hydroperoxide method}

The influence of the temperature in the range of 70 $110^{\circ} \mathrm{C}$, at the $\mathrm{CDT}: \mathrm{TBHP}$ mole ratio $3: 1$, the $\mathrm{Mo}(\mathrm{CO})_{6}: \mathrm{TBHP}$ mole ratio $0.5 \cdot 10^{-3}$, and the reaction time $120 \mathrm{~min}$ were investigated (Table 5).
At the preliminary selected initial parameters, the increase of the reaction temperature increased the ECDD yield in relation to both the CDT and TBHP introduced. The highest yield of the ECDD is achieved at $90^{\circ} \mathrm{C}$.

The influence of the mole ratio of CDT to TBHP on the yield of the ECDD in relation to the CDT and TBHP introduced is shown in Table 6 . The studies were carried out at the temperature $90^{\circ} \mathrm{C}$, the $\mathrm{Mo}(\mathrm{CO})_{6}: \mathrm{TBHP}$ mole ratio $0.5 \cdot 10^{-3}$, and the reaction time $120 \mathrm{~min}$.

The increase of the CDT:TBHP mole ratio decreases the ECDD yield in relation to the CDT introduced. A decrease of the ECDD yield is associated with a decrease of the CDT conversion. With increasing the CDT:TBHP mole ratio the concentration of the TBHP in reaction mixtures decreases. This causes a decline of the epoxidation rate. However, the ECDD yield in relation to the TBHP introduced is increased with the increase of the CDT:TBHP mole ratio.

The changes of the $\mathrm{Mo}(\mathrm{CO})_{6}: \mathrm{TBHP}$ mole ratio in the range $0.0001-0.001$ do not have a significant influence on the yield of the ECDD.

The influence of the reaction time on the yield of the ECDD in relation to the CDT and TBHP introduced is shown in Table 7. The studies were carried out at the

Table 4. The result of the CDT epoxidation under the PTC condition in relation to the temperature

\begin{tabular}{|l|l|l|l|l|l|l|l|}
\hline & \multicolumn{5}{c|}{ Temperature, ${ }^{\circ} \mathrm{C}$} \\
\hline & 20 & 35 & 50 & 60 & 70 & 80 \\
\hline $\mathrm{W} \mathrm{ECDD} / \mathrm{H}_{2} \mathrm{O}_{2}[\mathrm{~mole} \%]$ & 25.44 & 37.48 & 41.65 & 38.31 & 38.74 & 37.92 \\
\hline $\mathrm{W} \mathrm{ECDD/CDT}[\mathrm{mole} \%]$ & 26.03 & 38.12 & 43.17 & 40.13 & 39.75 & 38.66 \\
\hline
\end{tabular}

Table 5. The result of the CDT epoxidation by the $\mathrm{Mo}(\mathrm{CO})_{6} / \mathrm{TBHP}$ system in relation to the reaction temperature

\begin{tabular}{|l|c|c|c|c|c|}
\hline & \multicolumn{3}{|c|}{ Temperature $\left[^{\circ} \mathrm{C}\right]$} \\
\hline & 70 & 80 & 90 & 100 & 110 \\
\hline CDT/TBHP mole ratio & $3: 1$ & $3: 1$ & $3: 1$ & $3: 1$ & $3: 1$ \\
\hline $\mathrm{Mo}(\mathrm{CO})_{6} /$ TBHP mole ratio & 0.0005 & 0.0005 & 0.0005 & 0.0005 & 0.0005 \\
\hline Reaction time [h] & 2 & 2 & 2 & 2 & 2 \\
\hline ECDD yield/TBHP [mole\%] & 68.8 & 76.9 & 78.9 & 77.0 & 76.9 \\
\hline ECDD yield/CDT [mole\%] & 22.9 & 25.7 & 26.6 & 26.3 & 26.1 \\
\hline
\end{tabular}

Table 6. The result of the CDT epoxidation by the $\mathrm{Mo}(\mathrm{CO})_{6} / \mathrm{TBHP}$ system in relation to the CDT/TBHP mole ratio

\begin{tabular}{|l|c|c|c|c|c|}
\hline & \multicolumn{4}{c|}{ CDT/TBHP mole ratio } \\
\hline & 1 & 3 & 5 & 7 & 10 \\
\hline Temperature [ $\left.{ }^{\circ} \mathrm{C}\right]$ & 90 & 90 & 90 & 90 & 90 \\
\hline $\mathrm{Mo}(\mathrm{CO})_{6} / \mathrm{TBHP}$ mole ratio & 0.0005 & 0.0005 & 0.0005 & 0.0005 & 0.0005 \\
\hline Reaction time [h] & 2 & 2 & 2 & 2 & 2 \\
\hline ECDD yield /TBHP mole\%] & 50.2 & 26.6 & 16.6 & 12.5 & 9.5 \\
\hline ECDD yield /CDT [mole\%] & 48.9 & 78.9 & 83.3 & 89.5 & 96.4 \\
\hline
\end{tabular}

Table 7. The result of the CDT epoxidation by the $\mathrm{Mo}(\mathrm{CO})_{6} / \mathrm{TBHP}$ system in relation to the reaction time

\begin{tabular}{|c|c|c|c|}
\hline & \multicolumn{3}{|c|}{ Reaction time [min] } \\
\hline & 60 & 120 & 180 \\
\hline CDT/TBHP mole ratio & $3: 1$ & $3: 1$ & $3: 1$ \\
\hline $\mathrm{Mo}(\mathrm{CO})_{6} / \mathrm{TBHP}$ mole ratio & 0.0005 & 0.0005 & 0.0005 \\
\hline ECDD yield /TBHP [mole\%] & 54.4 & 68.0 & 78.5 \\
\hline ECDD yield /CDT [mole\%] & 18.3 & 22.9 & 26.4 \\
\hline Temperature $\left[{ }^{\circ} \mathrm{C}\right]$ & 90 & & \\
\hline ECDD yield /TBHP [mole\%] & 77.6 & 78.9 & 79.9 \\
\hline ECDD yield /CDT [mole\%] & 26.1 & 26.6 & 26.9 \\
\hline Temperature $\left[{ }^{\circ} \mathrm{C}\right]$ & 110 & & \\
\hline ECDD yield /TBHP [mole\%] & 76.0 & 76.9 & 77.4 \\
\hline ECDD yield /CDT [mole\%] & 25.8 & 26.1 & 26.3 \\
\hline
\end{tabular}


temperatures 70,90 , and $110^{\circ} \mathrm{C}$, at the CDT:TBHP mole ratio $3: 1$, and at the $\mathrm{Mo}(\mathrm{CO})_{6}$ : TBHP mole ratio $0.5 \cdot 10^{-3}$.

At low temperatures $\left(70^{\circ} \mathrm{C}\right)$, an increase in the reaction time increases the ECDD yield in relation to both the CDT and TBHP introduced. At higher temperatures (90 and $110^{\circ} \mathrm{C}$ ) prolongation of the reaction time do not have a significant influence on the yield of the ECDD.

\section{CONCLUSIONS}

The two phase catalytic epoxidation of cis,trans,trans1,5,9-cyclododecatriene with the aqueous hydrogen peroxide in the presence of the phase transfer catalyst was found to be an equally good method as the homogeneous catalytic epoxidation by the TBHP in the presence of $\mathrm{Mo}(\mathrm{CO})_{6}$. Comparison of the influence of the technological parameter of these two methods of the 1,2-epoxy-5,9cyclododecadiene synthesis indicates that the epoxidation proceeds somewhat better with the use of the TBHP.

\section{LITERATURE CITED}

(1) Brégeault J. -M.: Transition-metal complexes for liquid-phase catalytic oxidation: some aspects of industrial reactions and of emerging technologies, Dalton Transl., 2003, 3289.

(2) Choudary B. M., Kantam M. L., Santhi P. L.: New and ecofriendly options for the production of specialty and fine chemicals, Catal. Today, 2000, 57, 17.

(3) Sheldon R. A.: Selective catalytic synthesis of fine chemicals: opportunities and trends, J. Mol. Catal. A: Chem., 1996, 107,75 .

(4) Grigoropoulou G., Clark J. H., Elingsb J. A.: Recent developments on the epoxidation of alkenes using hydrogen peroxide as an oxidant, Green Chem., 2003, 5, 1.

(5) Venturello C., Alneri E., Ricci M.: A new effective catalytic system for epoxidation of olefins by hydrogen peroxide under phase-transfer conditions, J. Org. Chem., 1983, 48, 3831.

(6) Venturello C., D'Aloisio R.: Quaternary ammonium tetrakis(diperoxotungsto)-phosphate(3-) as a new class of catalysts for efficient alkene epoxidation with hydrogen peroxide, J. Org. Chem., 1988, 53, 1553.

(7) Ishii Y., Yamawaki K., Ura T., Yamada H., Yoshida T., Ogawa M.: Hydrogen peroxide oxidation catalyzed by heteropoly acids combined with cetylpyridinium chloride: Epoxidation of olefins and allylic alcohols ketonization of alcohols and diols and oxidative cleavage of 12 -diols and olefins, J. Org. Chem., 1988, 53, 3587.

(8) Arends I. W. C. E., Sheldon R. A.: Recent developments in selective catalytic epoxidations with $\mathrm{H}_{2} \mathrm{O}_{2}$, Topics Catal., 2002, 19, 133 - 141.

(9) Sharpless K. B., Verhoeven T. R.: Metal catalysed, highly selective oxygenation of olefins and acetylenes with tert-butyl hydroperoxide. Practical consideration and mechanisms, Aldrichim. Acta, 1979, 12, 63 - 74.

(10) Lewandowski G.: Epoxidation of (Z,E,E)-1,5,9cyclododecatriene with aqueous hydrogen peroxide by the method of phase transfer catalysis (PTC), Annals of the Polish Chemical Society, Year 2005, v. II, 421.

(11) Wagner Ch. D., Smith R. D., Peters E. D.: Anal. Chem., 1974, 19, 976. 